\title{
PENENTUAN KADAR FLAVONOID TOTAL DAN NILAI SPF EKSTRAK ETANOL DAUN BUAS-BUAS (Premna serratifolia L.) ASAL KABUPATEN MELAWI PROVINSI KALIMANTAN BARAT
}

\author{
Weni Puspita $^{* 1)}$, Heny Puspasari ${ }^{1)}$ \\ ${ }^{1}$ Akademi Farmasi Yarsi Pontianak \\ Jalan Panglima A'im, Pontianak Timur, Kalimantan Barat, Indonesia, 78232 \\ Email : weni.puspita.apt@gmail.com
}

\section{INTISARI}

Daun buas-buas (Premna serratifolia L.) mengandung flavonoid, saponin, polifenol dan terpenoid, yang berpotensi sebagai tabir surya. Penelitian ini bertujuan untuk mengetahui kadar flavonoid total dan nilai SPF (Sun Protection Factor) ekstrak etanol daun buas-buas (EEDB) dari Kabupaten Melawi Provinsi Kalimantan Barat menggunakan spektrofotometri UV-Vis. Daun buasbuas diekstraksi secara maserasi menggunakan pelarut etanol 70\%, kemudian filtrat yang diperoleh dipekatkan dengan penguap vakum putar hingga didapatkan ekstrak kental. Ekstrak tersebut ditentukan kadar flavonoidnya menggunakan spektrofotometri UV-Vis pada panjang gelombang 439 $\mathrm{nm}$, serta dilakukan penentuan nilai SPF pada konsentrasi 25, 50, 75, dan 100 ppm dengan spektrofotometer UV-Vis pada panjang gelombang 290-320 nm. Nilai SPF dihitung dan dianalisis secara deskriptif menggunakan metode Mansur. Hasil penelitian menunjukkan bahwa rata-rata kadar flavonoid total EEDB adalah 3,70 $\pm 0,02 \%$ dihitung sebagai kuersetin. Nilai SPF EEDB yang diperoleh dari variasi konsentrasi 25, 50, 75 dan 100 ppm secara berturut-turut yaitu 19,95 $\pm 0,02 ; 30,08 \pm 0,01$; $34,58 \pm 0,14$; dan 38,28 $\pm 0,12$, dimana nilai SPF tersebut termasuk kategori proteksi ultra.

Kata kunci: daun Premna serratifolia L., kadar flavonoid total, SPF (Sun Protection Factor), Spektrofotometri UV-Vis

\begin{abstract}
Premna serratifolia L. leaves contain flavonoids, saponins, polyphenols, and terpenoids, potentially act as sunscreens. The purpose of this study was to determine the flavonoid content and SPF (Sun Protection Factor) ethanol extract of Premna serratifolia L. leaves from Melawi Regency, West Kalimantan Province using UV-Vis spectrophotometer. The Premna serratifolia L. leaves were extracted by maceration using $70 \%$ ethanol solvent, then the filtrate obtained was concentrated with a rotary vacuum evaporator to obtain a thick extract. The extract was determined for its flavonoid content using UV-Vis spectrophotometer at a wavelength of $439 \mathrm{~nm}$, and the SPF value was determined at a concentration of $25,50,75$, and $100 \mathrm{ppm}$ with a UV-Vis spectrophotometer at a wavelength of 290-320 $\mathrm{nm}$. The SPF value was calculated and analyzed descriptively using the Mansur method. The result showed that the average flavonoid content of ethanol extract of Premna serratifolia L. leaves was $3.70 \pm 0.02 \%$ calculated as quercetin. The SPF EEDB values obtained from variations in concentrations of $25,50,75$, and $100 \mathrm{ppm}$ respectively were $19.95 \pm 0.02 ; 30.08 \pm 0.01$; $34.58 \pm 0.14$; and $38.28 \pm 0.12$, where the SPF value is included in the ultra protection category.
\end{abstract}

Key words: Premna serratifolia L. leaves, flavonoid content, SPF, UV-Vis Spectrophotometer

Corresponding author: 
Weni Puspita

Akademi Farmasi Yarsi Pontianak

Jalan Panglima A’im, Pontianak Timur, Kalimantan Barat, Indonesia, 78232

Email: weni.puspita.apt@gmail.com

\section{PENDAHULUAN}

Pengobatan herbal dengan tumbuhan semakin banyak diminati karena pengobatan herbal relatif tidak memiliki efek samping yang buruk bagi tubuh manusia. Salah satu tumbuhan yang menarik untuk diteliti adalah buas-buas (Premna serratifolia L.). Berdasarkan penelitian Wulandari dan Utomo, (2019) bahwa simplisia daun buas-buas mengandung steroid, terpenoid, fenolik, flavonoid, tanin, dan saponin. Menurut Kurniati, (2013) tanaman buas-buas mengandung senyawa bioaktif yang spesifik dari kelompok flavonoid antara lain luteolin, apigenin dan kuersetin, dimana flavonoid diketahui memiliki sifat sebagai penangkap radikal bebas atau bersifat antioksidan.

Penelitian lainnya menyebutkan ekstrak etanol daun buas-buas (Premna foetida reinw. Ex blume) yang berasal dari Kabupaten Sintang Provinsi Kalimantan Barat dengan ketinggian tempat tumbuh 1200 mdpl mengandung senyawa golongan flavonoid dengan kadar flavonoid total sebesar 0,4\% b/b dihitung sebagai kuersetin (Palpon., 2017). Ekstrak etanol daun buas-buas memiliki aktivitas antioksidan yang sangat kuat dengan nilai $\mathrm{IC}_{50}$ sebesar 20,66 $\mu \mathrm{g} / \mathrm{ml}$ (Puspita, dkk., 2020).

Adanya kandungan flavonoid dan antioksidan yang sangat kuat pada daun buas-buas diperkirakan memiliki aktivitas tabir surya. Menurut peraturan kepala BPOM RI Nomor HK.03.1.23.08.11.07517 Tahun 2011, definisi dari bahan tabir surya adalah bahan yang digunakan untuk melindungi kulit dari radiasi sinar UV dengan cara menyerap, memancarkan dan menghamburkan. Tabir surya telah banyak dikembangkan untuk melindungi manusia dari radiasi UV A dan UV B yang membahayakan. Tingkat proteksi pada tabir surya dikenal dengan istilah Sun Protection Factor (SPF).

Pertumbuhan dan perkembangan suatu tumbuhan dan kandungan metabolit sekunder sangat dipengaruhi oleh faktor lingkungan termasuk ketinggian tempat tumbuh (Depkes RI. 2000). Penelitian Sari (2015) menyatakan bahwa ekstrak daun sirsak yang berasal dari daerah dengan ketinggian 18 mdpl memiliki kadar flavonoid total paling tinggi, sedangkan ekstrak daun sirsak yang berasal dari daerah dengan ketinggian 234 mdpl memiliki kadar flavonoid total paling rendah. Flavonoid pada tanaman memerlukan gula dalam produksinya. Gula ini salah satunya diperoleh dari fotosintesis di sel yang mengandung klorofil yang dipengaruhi oleh intensitas cahaya. Intensitas cahaya ini juga akan dipengaruhi oleh ketinggian tempat tumbuh dimana semakin tinggi tempat tumbuh maka intensitas cahaya akan semakin kecil (Vickery, 1984).

Adanya kandungan flavonoid dalam daun buas-buas berpotensi menyerap sinar UV sehingga dapat digunakan sebagai tabir surya. Berdasarkan latar belakang tersebut, maka perlu dilakukan penelitian mengenai penetapan kadar flavonoid total dan nilai SPF ekstrak etanol daun buas-buas yang berasal dari kabupaten Melawi Provinsi Kalimantan Barat, sehingga potensi tumbuhan ini sebagai bahan aktif sediaan tabir surya dapat lebih dikembangkan.

\section{METODE PENELITIAN}

\section{Alat dan Bahan}

Alat yang digunakan dalam penelitian adalah alat-alat gelas, labu ukur, cawan porselen, mikro pipet, kertas saring, neraca analitik, penguap vakum putar, spektrofotometer UV-Vis. Bahan yang digunakan dalam penelitian ini adalah daun buas-buas (Premna serratifolia L.), metanol p.a, etanol p.a, etanol 70\%, etanol $96 \%$, aquadest, natrium asetat, alumunium klorida, kuersetin. 


\section{Jalannya Penelitian}

1. Determinasi Tanaman

Bagian tanaman yang digunakan sebagai sampel yaitu daun buas-buas yang masih segar diperoleh di Desa Nanga Nuak Kabupaten Melawi Provinsi Kalimantan Barat dengan ketinggian 780 mdpl. Determinasi dilakukan di Laboratorium Fakultas Pertanian dan Biologi Universitas Tanjungpura Pontianak.

2. Pembuatan serbuk simplisia

Daun buas-buas dibersihkan dari kotoran-kotoran yang menempel dengan cara mencucinya dengan air mengalir. Kemudian dilakukan perajangan terhadap daun buas-buas, selanjutnya dilakukan pengeringan menggunakan sinar matahari langsung. Kemudian dilakukan sortasi kering dan dihaluskan menjadi serbuk.

3. Pembuatan ekstrak etanol daun buas-buas

Sebanyak 2100 g simplisia daun buas-buas (Premna serratifolia L.) dimasukkan dalam bejana maserasi kemudian ditambahkan pelarut etanol $70 \%$ hingga volumenya diatas permukaan serbuk, lalu ditutup dan dibiarkan selama $3 \times 24$ jam sambil sesekali diaduk. Setelah 3x24 jam hasil maserasi disaring, ampas diperas sehingga diperoleh ekstrak cair. Ekstrak cair dipekatkan menggunakan penguap vakum putar pada suhu $45-50^{\circ} \mathrm{C}$ dan didapatkan ekstrak kental.

4. Penentuan panjang gelombang maksimum kuersetin

Penentuan panjang gelombang maksimum kuersetin dilakukan dengan pembacaan absorbansi larutan kuersetin pada rentang panjang gelombang 400 - $450 \mathrm{~nm}$. Hasil pembacaan absorbansi menunjukkan panjang gelombang maksimum standar baku kuersetin adalah $439 \mathrm{~nm}$. Panjang gelombang maksimum tersebut digunakan untuk mengukur serapan dari sampel ekstrak etanol daun buas-buas.

5. Penentuan operating time

Larutan kuersetin $100 \mathrm{ppm}$ diambil sebanyak $1 \mathrm{ml}$ ditambahkan dengan $0,1 \mathrm{ml} \mathrm{AlCl}_{3} 10 \%, 0,1 \mathrm{ml}$ natrium asetat $1 \mathrm{M}$ dan 2,8 $\mathrm{ml}$ aquadest. Larutan tersebut diukur absorbansinya pada panjang gelombang maksimum teoritis $415 \mathrm{~nm}$ dengan interval waktu 2 menit sampai diperoleh absorbansi yang stabil. Dibuat kurva hubungan antara absorbansi, waktu, dan ditentukan operating time.

6. Pembuatan larutan standar kuersetin

Ditimbang sebanyak $10 \mathrm{mg}$ kuersetin dan dilarutkan dalam $10 \mathrm{~mL}$ etanol p.a sebagai larutan standar kuersetin 1000 ppm. Dari larutan standar kuersetin 1000 ppm, kemudian dibuat beberapa konsentrasi yaitu 20, 30, 40, 50 dan $60 \mathrm{ppm}$. Sebanyak 0,5 ml larutan standar kuersetin ditambahkan $0,1 \mathrm{ml} \mathrm{AlCl}{ }_{3} 10 \%, 0,1 \mathrm{ml}$ natrium asetat $1 \mathrm{M}$ dan 2,8 ml aquadest. Campuran tersebut divortex hingga homogen, kemudian didiamkan selama operating time. Selanjutnya setiap konsentrasi larutan diukur absorbansinya menggunakan metode spektrofotometri UV-Vis pada panjang gelombang maksimum $439 \mathrm{~nm}$.

7. Pengukuran Serapan Larutan Blanko

Pengujian dilakukan dengan mencampurkan larutan kuersetin sebanyak $1 \mathrm{ml}$ dengan pelarut etanol p.a sampai volume $5 \mathrm{ml}$ dalam labu ukur. Kemudian dibiarkan selama 30 menit. Selanjutnya setiap konsentrasi larutan diukur absorbansinya menggunakan metode spektrofotometri UV-Vis pada panjang gelombang maksimum $439 \mathrm{~nm}$.

8. Penentuan kadar flavonoid total ekstrak etanol daun buas-buas

Sebanyak $20 \mathrm{mg}$ sampel ditimbang dan dilarutkan dalam $10 \mathrm{~mL}$ etanol, sehingga diperoleh konsentrasi $2000 \mathrm{ppm}$. Sebanyak 0,5 ml sampel uji ditambahkan dengan 1,5 ml metanol 96\%, kemudian ditambahkan $0,1 \mathrm{ml} \mathrm{AlCl}_{3} 10 \%, 0,1 \mathrm{ml}$ natrium asetat $1 \mathrm{M}$ dan 2,8 ml aquadest. Campuran tersebut divortex hingga homogen, kemudian dibiarkan selama 60 menit. Selanjutnya setiap konsentrasi larutan diukur absorbansinya menggunakan metode spektrofotometri UV-Vis pada panjang gelombang maksimum $439 \mathrm{~nm}$

Penentuan Kadar Flavonoid Total Dan Nilai Spf Ekstrak Etanol Daun Buas-Buas (Premna serratifolia L.) Asal Kabupaten Melawi Provinsi Kalimantan Barat (Puspita) 


\section{Penentuan Nilai SPF Ekstrak Etanol Daun Buas-buas Secara In Vitro}

Penentuan aktivitas tabir surya dilakukan dengan menentukan nilai SPF secara in vitro dengan spektrofotometri UV-Vis. Spektrofotometer UV-Vis dikalibrasi terlebih dahulu dengan menggunakan etanol 96\%. Dimasukkan etanol 96\% kedalam kuvet dimasukkan ke dalam spektrofotometer UV-Vis untuk proses kalibrasi. Dibuat larutan induk ekstrak etanol daun buasbuas dengan konsentrasi 1000 ppm, kemudian dilakukan pengenceran dengan variasi konsentrasi 25, 50, 75 dan 100 ppm menggunakan etanol 96\% sebanyak $10 \mathrm{~mL}$ dan dicampur hingga homogen dalam labu takar. Dibuat kurva serapan uji dalam kuvet, dengan panjang gelombang antara 290-320 nm menggunakan etanol 96\% sebagai blanko. Kemudian ditetapkan serapan dengan interval $5 \mathrm{~nm}$. Hasil absorbansi masing-masing konsentrasi ekstrak etanol daun buas-buas (EEDB) dicatat dan kemudian nilai SPFnya dihitung dengan menggunakan metode Mansur (Mansur dkk, 1986).

\section{Analisis Data}

Analisis data yang digunakan adalah metode deskriptif yang didasarkan pada data hasil penetapan kadar flavonoid, dimana kadar flavonoid dapat dihitung menggunakan rumus (Basset dkk., 1994):

$$
\% \text { kadar }=\frac{\mathrm{C}(\mathrm{mg} / \mathrm{L}) \times \mathrm{V} \times \mathrm{Fp} \times 10^{-3}}{\text { Berat sampel }(\mathrm{g})} \times 100 \%
$$

Keterangan :

C : Konsentrasi sampel

$\mathrm{V}$ : Volume sampel

Fp: Faktor pengenceran

Nilai SPF dianalisis secara deskriptif setelah dihitung menggunakan metode Mansur dkk, (1986) dengan rumus berikut ini:

$$
\mathrm{SPF}=\mathrm{CF} \times \sum_{290}^{\mathrm{a} 20} \mathrm{EE}(\lambda) \times I(a) \times A(\lambda)
$$

Keterangan:

$\mathrm{EE}=$ Spektrum efek eritemal

I = Intensitas spektrum sinar

$\mathrm{A}=$ Serapan produk tabir surya

$\mathrm{CF}=$ Faktor koreksi (10)

Nilai EE x I adalah konstan dan ditunjukkan pada Tabel I. berikut (Mansur dkk, 1986) :

Tabel I. Nilai EE x I Pada Panjang Gelombang 290-320 nm

\begin{tabular}{cc}
\hline Panjang Gelombang $(\mathbf{n m})$ & EE $\mathbf{x}$ I \\
\hline 290 & 0,0150 \\
295 & 0,0817 \\
300 & 0,2874 \\
305 & 0,3278 \\
310 & 0,1864 \\
315 & 0,0839 \\
320 & 0,0180 \\
\hline Total & 1
\end{tabular}

JIFFK Vol. 18, No. 1, Bulan Juni 2021, Hal 24-30 


\section{HASIL DAN PEMBAHASAN}

\section{Penentuan Kadar Flavonoid Ekstrak Etanol Daun Buas-buas}

Penelitian ini diawali dengan ekstraksi daun buas-buas menggunakan pelarut etanol $70 \%$ dikarenakan sifatnya polar sehingga diharapkan seluruh jenis flavonoid ikut terekstraksi. Ekstrak yang diperoleh dipekatkan dengan penguap vakum putar, dimana hasil akhir berupa ekstrak kental yang di dapatkan dari 2100 gram simplisia diperoleh ekstrak kental kurang lebih 450 gram dengan hasil rendemen $21,42 \%$. Hasil rendemen yang tinggi menunjukkan bahwa senyawa-senyawa kimia yang dapat tersari dalam ekstrak juga cukup besar. Hal ini dimungkinkan karena banyaknya senyawa kimia yang ada dalam simplisia.

Tabel II. Hasil pengukuran absorbansi larutan standar kuersetin pada panjang gelombang maksimum $439 \mathrm{~nm}$

\begin{tabular}{cc}
\hline Konsentrasi (ppm) & Absorbansi \\
\hline 20 & 0,157 \\
30 & 0,266 \\
40 & 0,358 \\
50 & 0,433 \\
60 & 0,510 \\
\hline
\end{tabular}

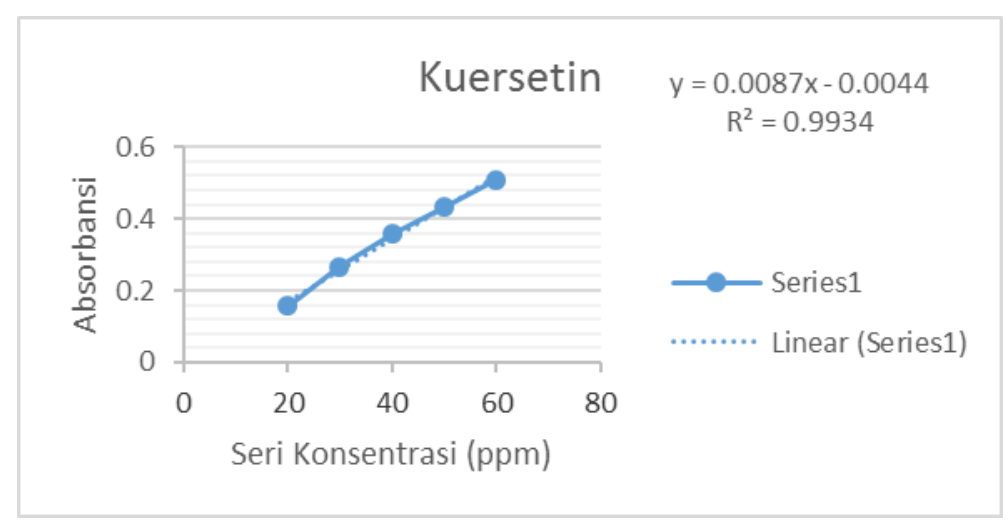

Gambar 1. Kurva baku kuersetin pada panjang gelombang maksimum 439 nm

Tabel III. Hasil penetapan kadar flavonoid total ekstrak etanol daun buas-buas

\begin{tabular}{ccccc}
\hline Replikasi & Absorbansi & $\begin{array}{c}\text { Kandungan Ekivalen } \\
(\mathbf{p p m})\end{array}$ & $\begin{array}{c}\text { Kadar Flavonoid } \\
\text { Total }(\%)\end{array}$ & $\begin{array}{c}\text { Rata-rata Kadar } \\
\text { Flavonoid Total } \\
(\%)\end{array}$ \\
\hline 1 & 0,638 & 73,84 & 3,69 & \\
2 & 0,640 & 74,07 & 3,70 & $3,70 \pm 0,02$ \\
3 & 0,643 & 74,41 & 3,72 & \\
\hline
\end{tabular}

Hasil pengukuran absorbansi larutan standar kuersetin dan kurva baku kuersetin pada panjang gelombang maksimum $439 \mathrm{~nm}$ yang dapat dilihat pada tabel II dan gambar 1, dapat disimpulkan bahwa semakin tinggi konsentrasi yang digunakan maka semakin tinggi pula absorbansi yang diperoleh. Hasil persamaan dari kurva baku kuersetin dapat digunakan untuk menghitung kadar senyawa flavonoid total pada ekstrak sampel. Penelitian Palpon (2017) menyatakan bahwa daun buas-buas yang berasal dari daerah Kabupaten Sintang Provinsi 
Kalimantan Barat memiliki kadar flavonoid total sebesar $0,4 \% \mathrm{~b} / \mathrm{b}$ dihitung sebagai kuersetin. Berdasarkan hasil penelitian pada tabel III, rerata kandungan flavonoid ekstrak etanol daun buasbuas (Premna serratifolia L.) yang berasal dari Kabupaten Melawi Provinsi Kalimantan Barat sebesar 3,70 $\pm 0,02 \%$ dihitung sebagai kuersetin. Hasil penelitian tersebut menunjukkan bahwa daun buas-buas (Premna serratifolia L.) yang berasal dari daerah Kabupaten Melawi Provinsi Kalimantan Barat dengan ketinggian tempat tumbuh lebih rendah yaitu 780 mdpl memiliki kadar flavonoid yang lebih tinggi dibandingkan daun buas-buas (Premna foetida reinw. Ex blume) yang berasal dari daerah Kabupaten Sintang Provinsi Kalimantan Barat. Hal ini dipengaruhi oleh daerah Kabupaten Melawi Provinsi Kalimantan Barat yang memiliki ketinggian tempat tumbuh lebih rendah, sehingga intensitas cahaya matahari akan menjadi lebih besar yang mengakibatkan proses fotosintesis dan kadar flavonoid akan menjadi lebih tinggi.

\section{Hasil Penentuan Nilai SPF (Sun Protection Factor) Ekstrak Etanol Daun Buas-buas}

Penentuan nilai SPF dilakukan dengan mengukur absorbansi dengan metode spektrofotometer UV-Vis pada panjang gelombang antara 290-320 nm (UV B). Metode ini paling umum digunakan untuk pengujian aktivitas tabir surya dan juga merupakan metode yang sangat sederhana, cepat, serta bahan kimia dan sampel yang digunakan sedikit. Suatu tabir surya dikatakan dapat memberikan perlindungan bila memiliki nilai SPF minimal 2 dan kategori yang baik apabila sampel uji memiliki nilai SPF di atas 15 yang tergolong dalam tabir surya kategori proteksi ultra. Hal ini dikarenakan nilai SPF diatas 15 akan mampu memberikan perlindungan lebih baik dari risiko kerusakan kulit jangka panjang, seperti kanker kulit. Selain itu, SPF diatas 15 mampu melindungi kulit lebih lama dari paparan sinar matahari (Wilkinson \& Moore, 1982). Hasil nilai SPF ekstrak etanol daun buas-buas dapat dilihat pada tabel IV berikut.

Tabel IV. Nilai SPF (Sun Protection Factor) Ekstrak Etanol Daun Buas-buas

\begin{tabular}{ccc}
\hline $\begin{array}{c}\text { Konsentrasi Ekstrak } \\
(\mathbf{p p m})\end{array}$ & Nilai SPF & Tipe Proteksi \\
\hline 25 & $19,95 \pm 0,02$ & Proteksi ultra \\
50 & $30,08 \pm 0,01$ & Proteksi ultra \\
75 & $34,58 \pm 0,14$ & Proteksi ultra \\
100 & $38,28 \pm 0,12$ & Proteksi ultra \\
\hline
\end{tabular}

Berdasarkan tabel IV, diperoleh nilai SPF pada konsentrasi 25, 50, 75 dan 100 ppm secara berturut-turut yaitu $19,95 \pm 0,02 ; 30,08 \pm 0,01 ; 34,58 \pm 0,14$; dan 38,28 $\pm 0,12$ dimana nilai SPF tersebut termasuk tipe kategori proteksi ultra. Nilai SPF tersebut menunjukkan bahwa ekstrak etanol daun buas-buas pada semua konsentrasi uji dapat digunakan sebagai bahan tabir surya yang mampu memberikan perlindungan dari sinar UV A dan UV B. Konsentrasi ekstrak merupakan faktor yang mempengaruhi penentuan aktivitas tabir surya yang ditunjukkan dengan adanya nilai SPF. Faktor ini dapat menambah atau mengurangi penyerapan UV pada setiap tabir surya. Aktivitas tabir surya dikarenakan adanya kadar flavonoid yang cukup tinggi pada daun buas-buas yaitu sebesar $3,70 \pm 0,02 \%$ dihitung sebagai kuersetin. Adapun mekanisme dari flavonoid dalam tabir surya adalah adanya ikatan rangkap terkonjugasi pada senyawa flavonoid menyebabkan suatu molekul

JIFFK Vol. 18, No. 1, Bulan Juni 2021, Hal. 24-30 
dapat mengalami transisi elektronik, sehingga molekul tersebut dapat menyerap radiasi pada daerah ultraviolet (Supratman, 2010).

\section{KESIMPULAN}

Berdasarkan hasil penelitian yang telah dilakukan, maka dapat disimpulkan bahwa rata-rata kadar flavonoid total ekstrak etanol daun buas-buas (EEDB) adalah 3,70 $\pm 0,02 \%$ dihitung sebagai kuersetin. Nilai SPF EEDB yang diperoleh dari variasi konsentrasi 25, 50, 75 dan 100 ppm secara berturut-turut yaitu $19,95 \pm 0,02 ; 30,08 \pm 0,01 ; 34,58 \pm 0,14$; dan $38,28 \pm 0,12$, dimana nilai SPF tersebut termasuk tipe kategori proteksi ultra.

\section{UCAPAN TERIMA KASIH}

Penulis ucapkan terima kasih kepada Direktorat Riset dan Pengabdian Masyarakat, Kementerian Riset, Teknologi, dan Pendidikan Tinggi atas dukungan yang diberikan kepada peneliti berupa bantuan dana penelitian yang menunjang berlangsungnya penelitian ini dengan baik.

\section{DAFTAR PUSTAKA}

Basset, J., R. C., Denney, G.H., Jeffrey, J., and Mendhom., 1994, Buku Ajar Vogel Kimia Analisis Kuantitatif Anorganik, EGC, Jakarta, 846-848.

Depkes RI, 2000. Parameter Standar Umum Ekstrak Tumbuhan Obat, Direktorat Jendral Pengawasan Obat dan Makanan, Jakarta, 28, 30, 32, 35.

Kurniati, R. I., 2013. Uji Aktivitas Antioksidan Fraksi Etanol Daun Buas-Buas (Premna cordifolia Linn.) dengan Metode DPPH (2,2-difenil-1-pikrilhidrazil). Jurnal Mahasiswa Farmasi Fakultas Kedokteran UNTAN, 3(1).

Mansur, J.S, Breder, M. N. R, Mansur, M. C. A, Azulary, R.D. 1986, Determination of Sun Protection Factor for Spectrophotometry, An Bras Dermatol. 62:121-124.

Palpon D, N., 2017, Penetapan Kadar Flavonoid Total Ekstrak Etanol Daun buas- buas (Premna foetida reinw. Ex blume). Karya Tulis Ilmiah. Akademi Farmasi Yarsi, Pontianak.

Puspita, W, Sari, D.Y., dan Rahman I.R., 2020, Uji Aktivitas Antioksidan Ekstrak Etanol Daun Buas-buas (Premna serratifolia L.) Asal Kabupaten Melawi Provinsi Kalimantan Barat Dengan Metode DPPH, Jurnal Insan Farmasi Indonesia, 3(2), 405-412.

Sari, A. K, 2015, Penetapan Kadar Polifenol Total, Flavonoid Total, Dan Uji Aktivitas Antioksidan Ekstrak Etanol Daun Sirsak (Annona muricata) Dari Jember Pada Ketinggian Tanah Yang Berbeda. Skripsi. Universitas Jember.

Supratman, U., 2010, Elusidasi Struktur Senyawa Organik, Widya Padjajaran Bandung

Vickery, A, 1984, Ekologi Hutan Indonesia. UGM Press. Jogjakarta.

Wilkinson, J. B., dan Moore, R. J., 1982, Harry's Cosmeticology $7^{\text {th }}$ Ed, Chemical Publishing Company, New York.

Wulandari, R., dan Utom, P. P., 2019, Skrinning Fitokimia dan Aktivitas Antioksidan Teh Herbal Daun Buas-buas (Premna cordifolia Roxb.). Jurnal Dinamika Penelitian Industri, 30(1) : 117122. 